\title{
Forecasting the Total Power of China's Agricultural Machinery Based on BP Neural Network Combined Forecast Method
}

\author{
Jinyan $\mathrm{Ju}^{1}$, Lin $\mathrm{Zhao}^{1}$, and Jinfeng Wang ${ }^{2}$ \\ ${ }^{1}$ School of Mechanical Engineering, Heilongjiang Institute of Science and Technology, \\ Harbin 150027, China \\ jujinyan2007@yahoo.cn \\ ${ }^{2}$ School of Engineering, Northeast Agricultural University, Harbin 150030, China
}

\begin{abstract}
In view of the limitations of single forecast model, forecasted results of different models will have some differences, in order to improve the forecast precision and the forecast results reliability, on the basis of determining the single forecast model for total power of China's agricultural machinery, the nonlinear combined forecast model for total power of agricultural machinery was established based on BP neural network using MATLAB software, and then the model was trained and simulated. The simulation results show that the fitting mean absolute percentage error of nonlinear combined forecast model is $0.59 \%$, which is lower than $2.57 \%, 2.66 \%$ and $2.09 \%$ of exponential model, GM $(1,1)$ model and cubic exponential smoothing model .The established models were validated using original data of China's total power of agricultural machinery from 2009 to 2011, validation results show that the combined forecast model has the lowest forecast error $0.64 \%$, the validation effect is the best, which can improve the forecast precision for total power of China's agricultural machinery. The total power of China's agricultural machinery was forecasted from 2012 to 2020 using the combined model, and the forecast results show that the total power of China's agricultural machinery will maintain a rapid growth trend in the next few years; it will be 1223987.1 MW by 2015 and 1603498.2 MW by 2020 .
\end{abstract}

Keywords: total power of agricultural machinery, BP neural network, combined forecast, simulation ${ }^{1}$.

\section{Introduction}

The total power of agricultural machinery means the sum of all mechanical power used for agriculture, forestry, animal husbandry, fishery production and transportation, which reflects the general development level of agricultural mechanization, and is the main planning index for the development of agricultural mechanization. At present, the main methods to forecast the total power of agricultural machinery are linear regression, moving average, grey $\operatorname{GM}(1,1)$ model, exponential smoothing, curve

\footnotetext{
${ }^{1}$ Supported by Youth Foundation of Heilongjiang province Scientific Committee (Project no. QC2011C007).
} 
fitting, data envelopment analysis, neural network model, combined forecast and so on [1-4] These methods each have its advantages and disadvantages, and the forecast results are different too.

This paper chose three kinds of forecast method, which are exponential model, cubic exponential smoothing and grey $\operatorname{GM}(1,1)$ respectively, to establish the single forecasting model for the total power of China's agricultural machinery. In view of the limitations of single forecast model [3-5], in order to improve the forecast precision and the forecast results reliability, the author combined forecasting results of different models together, making up for each other's deficiencies. Due to BP neural network has the ability to approximate any nonlinear function; the nonlinear combined forecast model based on BP neural network was established. Through comparing the forecast accuracy of the four developed forecast models, the nonlinear combined forecast model based on BP neural network has the best fitting effect and the forecast accuracy. Therefore, a new method for the forecast of total power of China's agricultural machinery is obtained, the forecast results can provide important theory references for China's farm machinery department to make the development planning of agricultural mechanization, publish relevant policies and apply for the financial support.

\section{Forecasting Models}

\subsection{Exponential Model}

As shown in table 1, the original statistical data of the total power of China's agricultural machinery is growing along with time, original time series from 1985 to 2008 can be fitted by curve models using SPSS software. The fitting results show that the exponential model has the best fitting effect, the determination coefficient $R^{2}=0.994$, the fitting accuracy is higher, the model is significant, and the obtained forecast model is

$$
Y=199591.631 \mathrm{e}^{0.058 x}
$$

Where $Y$ is the total power of agricultural machinery, unit: $\mathrm{MW} ; x$ is the time variable, corresponding value from 1985 to 2008 is respectively from 1 to 24 .

The total power of China's agricultural machinery from 1985 to 2008 were fitted with Eq.1, the results are shown in table 1, and the fitting mean absolute percentage error (MAPE) is $2.57 \%$.

\subsection{Grey GM $(1,1)$ Forecast Model}

Grey GM $(1,1)$ forecast model is suitable for data sequence which has small fluctuate along with time sequence, and its short-term forecast accuracy is higher[2,5]. The basic form of grey GM $(1,1)$ model is shown as follows:

$$
x^{(0)}(k)+a z^{(1)}(k)=b \quad(k=1,2, \cdots, n)
$$


If the original data sequence is given $X^{(0)}: X^{(0)}=\left(x^{(0)}(1), x^{(0)}(2), \cdots, x^{(0)}(n)\right)$, Where $x^{(0)}(k) \geq 0, k=1,2, \cdots, n$. Accumulating the original data sequence for one time to obtain the new data sequence $X^{(1)}, \quad X^{(1)}=\left(x^{(1)}(1), x^{(1)}(2), \cdots, x^{(1)}(n)\right.$, Where $x^{(1)}(k)=\sum_{i=1}^{k} x^{(0)}(i), k=1,2, \cdots, n$.The obtained new data sequence is a monotone growth curve, which increases the regularity of original data, and weakens the volatility. Sequence $Z^{(1)}$ is constructed by $X^{(1)}$.

$$
Z^{(1)}=\left(z^{(1)}(2), z^{(1)}(3), \cdots z^{(1)}(n)\right)
$$

Where $Z^{(1)}(k)=0.5\left(x^{(1)}(k)+x^{(1)}(k-1)\right), k=2,3 \cdots, n$.Provided that parameter column $\hat{a}=[a, b]^{\mathrm{T}}$, and

$$
Y=\left[\begin{array}{c}
x^{(0)}(2) \\
x^{(0)}(3) \\
\vdots \\
x^{(0)}(n)
\end{array}\right], \quad B=\left[\begin{array}{cc}
-z^{(1)}(2) & 1 \\
-z^{(1)}(3) & 1 \\
\vdots & \vdots \\
-z^{(1)}(n) & 1
\end{array}\right]
$$

Then the least square estimation of parameter column for Eq. 2 satisfies :

$$
\hat{a}=\left(B^{\mathrm{T}} B\right)^{-1} B^{\mathrm{T}} Y=\left[\begin{array}{c}
-0.059335 \\
202182.883
\end{array}\right]
$$

Then the equation $\frac{d x^{(1)}}{d t}+a x^{(1)}=b$ is called the whitening differential equation for Eq.2, and also called shadow equation, this whitening differential equation can be solved by MATLAB, and then the result is obtained:

$$
x^{(1)}(k)=3616630.945 \mathrm{e}^{0.059335(k-1)}-3407505.95 \quad(k=1,2, \cdots n)
$$

Restore value:

$$
x^{(0)}(k+1)=\hat{x}^{(1)}(k+1)-\hat{x}^{(1)}(k)
$$

The total power of agricultural machinery from 1985 to 2008 can be estimated using Eq.4 and Eq.5. The results are shown in table 1, which show that the fitting mean absolute percentage error is $2.66 \%$.

\subsection{Cubic Exponential Smoothing Model}

The development of the total power of agricultural machinery not only has great relationship with that year's social development but also with the recent year's development, and cubic exponential smoothing method is suitable for this kind of 
Table 1. Fitted results and errors of total power of China's agricultural machinery using different models

\begin{tabular}{|c|c|c|c|c|c|c|c|c|c|}
\hline \multirow{2}{*}{ years } & \multirow{2}{*}{$\begin{array}{l}\text { actual } \\
\text { value } \\
\text { /MW }\end{array}$} & \multicolumn{2}{|c|}{$\begin{array}{l}\text { exponential } \\
\text { model }\end{array}$} & \multicolumn{2}{|c|}{$\begin{array}{c}\text { grey } \operatorname{GM}(1,1) \\
\text { model }\end{array}$} & \multicolumn{2}{|c|}{$\begin{array}{l}\text { cubic exponential } \\
\text { smoothing model }\end{array}$} & \multicolumn{2}{|c|}{$\begin{array}{c}\text { BP neural network } \\
\text { combined forecast } \\
\text { model }\end{array}$} \\
\hline & & $\begin{array}{l}\text { fitted } \\
\text { values } \\
\text { /MW }\end{array}$ & $\begin{array}{l}\text { relative } \\
\text { errors/\% }\end{array}$ & $\begin{array}{l}\text { fitted } \\
\text { values } \\
\text { /MW }\end{array}$ & $\begin{array}{l}\text { relative } \\
\text { errors/\% }\end{array}$ & $\begin{array}{l}\text { fitted } \\
\text { values } \\
\text { /MW }\end{array}$ & $\begin{array}{l}\text { relative } \\
\text { errors/\% }\end{array}$ & $\begin{array}{l}\text { fitted } \\
\text { values } \\
\text { /MW }\end{array}$ & $\begin{array}{l}\text { relative } \\
\text { errors } / \%\end{array}$ \\
\hline 1985 & 209125 & 211588 & 1.18 & 209125 & 0 & & & & \\
\hline 1986 & 229500 & 224305 & 2.26 & 221085 & 3.67 & & & & \\
\hline 1987 & 248360 & 237787 & 4.26 & 234600 & 5.54 & 233575 & 5.95 & 247858 & 0.20 \\
\hline 1988 & 265750 & 252079 & 5.14 & 248941 & 6.32 & 261097 & 1.75 & 266613 & 0.32 \\
\hline 1989 & 280670 & 267230 & 4.79 & 264159 & 5.88 & 284861 & 1.49 & 280182 & 0.17 \\
\hline 1990 & 287077 & 283292 & 1.32 & 280307 & 2.36 & 302496 & 5.37 & 287238 & 0.06 \\
\hline 1991 & 293886 & 300318 & 2.19 & 297443 & 1.21 & 307194 & 4.53 & 293757 & 0.04 \\
\hline 1992 & 303084 & 318369 & 5.04 & 315625 & 4.14 & 309304 & 2.05 & 305376 & 0.76 \\
\hline 1993 & 318166 & 337504 & 6.08 & 334920 & 5.27 & 314824 & 1.05 & 319730 & 0.49 \\
\hline 1994 & 338025 & 357790 & 5.85 & 355393 & 5.14 & 329274 & 2.59 & 338722 & 0.21 \\
\hline 1995 & 361181 & 379294 & 5.02 & 377119 & 4.41 & 351863 & 2.58 & 362007 & 0.23 \\
\hline 1996 & 385469 & 402092 & 4.31 & 400172 & 3.81 & 379589 & 1.53 & 388287 & 0.73 \\
\hline 1997 & 420156 & 426259 & 1.45 & 424635 & 1.07 & 408479 & 2.78 & 415810 & 1.03 \\
\hline 1998 & 452077 & 451879 & 0.04 & 450593 & 0.33 & 448562 & 0.78 & 449158 & 0.65 \\
\hline 1999 & 489961 & 479039 & 2.23 & 478137 & 2.41 & 486245 & 0.76 & 482232 & 1.58 \\
\hline 2000 & 525736 & 507831 & 3.41 & 507366 & 3.49 & 528393 & 0.51 & 518190 & 1.44 \\
\hline 2001 & 551721 & 538354 & 2.42 & 538382 & 2.42 & 567439 & 2.85 & 553629 & 0.35 \\
\hline 2002 & 579299 & 570711 & 1.48 & 571293 & 1.38 & 592537 & 2.29 & 583607 & 0.74 \\
\hline 2003 & 603865 & 605013 & 0.19 & 606216 & 0.39 & 615896 & 1.99 & 613727 & 1.63 \\
\hline 2004 & 640279 & 641377 & 0.17 & 643274 & 0.47 & 636173 & 0.64 & 643405 & 0.49 \\
\hline 2005 & 683978 & 679927 & 0.59 & 682598 & 0.20 & 671016 & 1.90 & 680827 & 0.46 \\
\hline 2006 & 725221 & 720793 & 0.61 & 724325 & 0.12 & 718664 & 0.90 & 725283 & 0.01 \\
\hline 2007 & 765896 & 764116 & 0.23 & 768603 & 0.35 & 765317 & 0.08 & 770469 & 0.60 \\
\hline 2008 & 821904 & 810042 & 1.44 & 815588 & 0.77 & 809243 & 1.54 & 815623 & 0.76 \\
\hline
\end{tabular}


change trend, especially when the change trend continues for a period, this method can also be used for middle or long term forecast [4,7]. The basic form of the model is

$$
Y_{t+T^{\prime}}=a_{t}+b_{t} T^{\prime}+\frac{1}{2} c_{t} T^{2}
$$

Where $Y_{t+T}$ is the forecasted value of the total power of agricultural machinery, $t$ is the starting year for forecasting, $a_{t} 、 b_{t}, c_{t}$ are smoothing coefficients,$T^{\prime}$ is the number of time cycle for forecasting.

According to the statistical data of total power of agricultural machinery from 1985 to 2008 as shown in table 1 , then cubic exponential smoothing model was obtained:

$$
Y_{2008+T^{\prime}}=819169.19+49211.63 T^{\prime}+2566.02 T^{\prime 2}
$$

The total power of agricultural machinery from 1987 to 2008 can be estimated using cubic exponential smoothing equation 7 , the results are shown in table 1 , which show that the fitting mean absolute percentage error is $2.09 \%$.

\section{$3 \quad$ Nonlinear Combined Forecast Model Based on BP Neural Network}

In view of the limitations of single forecast model, in order to improve the forecast precision and the forecast results reliability, the author combined forecast results of different models together, making up for each other's deficiencies, and then the combined forecast model was established to forecast the total power of agricultural machinery. Due to BP neural network has a series of excellent characteristics such as nonlinear, robustness, adaptive, self-organization, and especially is suitable to establish nonlinear forecast model [7-9]. Therefore, the nonlinear combined forecast model based on BP neural network was established, which can reflect the information contained in the three forecast models, and the nonlinear mapping relationship between each single forecasting results and actual values was constructed.

\subsection{Basic Steps for Modeling}

(1) Ascertaining the input and output vector. The forecasted values of total power of agricultural machinery from 1987 to 2008, which are obtained through the established three forecast models, are taken as the neural network input vector $(P)$, the actual values of the total power of agricultural machinery are taken as the neural network output vector $(T)$.The input and output layer nodes of neural network are ascertained according to the actual problem, namely, the input layer has three nodes, and the output layer has one node, so the nonlinear mapping relationship between each single forecasting results and actual values was constructed. In this paper the basic form of nonlinear forecast model is $Y^{\prime}=f\left(x_{1}, x_{2}, x_{3}\right)$, where $x_{i}(i=1,2,3)$ is respectively the forecast results of exponential model, grey forecast model and cubic exponential smoothing model, $Y^{\prime}$ is the neural network output vector, $f$ is the nonlinear function decided by neural network weights and thresholds. 
(2) Ascertaining the hidden layer and hidden layer nodes. A network with a hidden layer and a linear output layer can approximate any rational function, and the forecasting accuracy can be improved by increasing the number of hidden layer nodes $[7,8]$. Therefore, in this paper BP neural network structure is adopted one hidden layer, namely the structure is $3-j-1$, where $j$ is the number of hidden layer node, $j$ can be determined according to the relationship between error and its number of nodes, and the number of node can be determined by gradually increasing or reducing method $[8,9]$.

(3) Selecting transfer function and training function. The transfer function of hidden layer was selected Sigmoid, the output layer was selected Pureline, and the training function was selected Trainlm.

\subsection{The Simulation of BP Neural Network}

BP neural network is established and simulated with MATLAB. In order to prevent partial neuron nodes supersaturated, the original data are normalized with mapminmax function before the network is trained, namely $[\mathrm{X}, \mathrm{ps}]=\operatorname{mapminmax}(\mathrm{P})$, where $\mathrm{X}$ is the obtained normalized data, structural body ps records the standardization mapping relationship. The new input data also need to be normalized using mapminmax function, namely making X1 = mapminmax (' apply ', P1, ps). In order to ensure the new input data belong to $[-1,1]$, in the process of normalization original data, a large enough value can be input as the maximum value of original data in advance. Finally, normalized data are recovered with $\mathrm{T}=$ mapminmax (' reverse ',t, ps). The training parameters of the network need to be set.

Finally when the number of nodes is 2 , the fitting effect and the generalization ability of network are better, the determined network structure is 3-2-1, the training results further analysis curves is shown in figure 1.

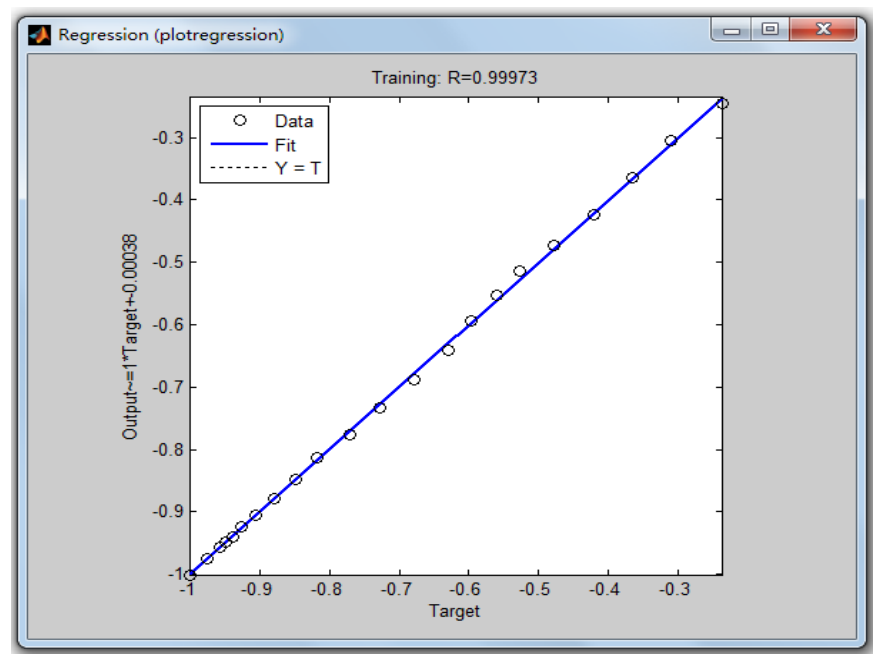

Fig. 1. Training result analysis graph of BP neural network combined model for total power of China's agricultural machinery 
As shown in figure 1, the abscissa is target outputs, ordinate is network output, the ideal regression straight line is a solid line, and the optimum regression straight is a dotted line. The linear regression relationship between the network output and target output is shown in this figure, the changing rate value $\mathrm{R}$ is more close to 1 , which means the network output and target output are more closed, the network performance is better. As shown in figure 2, the R value is 0.99973 , which means the network has very good performance. At this time the fitting values of the total power of agricultural machinery are shown in table 1 , and the fitting average error is $0.59 \%$. The total power of agricultural machinery from 2009 to 2011 were used as the test samples to validate the generalization ability for the established model, forecasting values of the test samples are shown in table 2, the average forecast error is $0.64 \%$, which has higher precision, and stronger generalization ability.

Table 2. Forecasted results and errors of test samples of total power of China's agricultural machinery

\begin{tabular}{|c|c|c|c|c|c|c|c|c|c|}
\hline \multirow{2}{*}{ years } & \multirow{2}{*}{$\begin{array}{c}\text { actual } \\
\text { values } \\
\text { /MW }\end{array}$} & \multicolumn{2}{|c|}{$\begin{array}{l}\text { exponential } \\
\text { model }\end{array}$} & \multicolumn{2}{|c|}{$\begin{array}{c}\text { grey } \operatorname{GM}(1,1) \\
\text { model }\end{array}$} & \multicolumn{2}{|c|}{$\begin{array}{l}\text { cubic exponential } \\
\text { smoothing model }\end{array}$} & \multicolumn{2}{|c|}{$\begin{array}{c}\text { BP neural network } \\
\text { combined forecast } \\
\text { model }\end{array}$} \\
\hline & & $\begin{array}{c}\text { fitted } \\
\text { values } \\
\text { /MW }\end{array}$ & $\begin{array}{c}\text { relative } \\
\text { errors } \\
1 \%\end{array}$ & $\begin{array}{l}\text { fitted } \\
\text { values } \\
\text { /MW }\end{array}$ & $\begin{array}{c}\text { relative } \\
\text { errors } \\
1 \%\end{array}$ & $\begin{array}{l}\text { fitted } \\
\text { values } \\
\text { /MW }\end{array}$ & $\begin{array}{l}\text { relative } \\
\text { errors } \\
1 \%\end{array}$ & $\begin{array}{l}\text { fitted } \\
\text { values } \\
\text { /MW }\end{array}$ & $\begin{array}{c}\text { relative } \\
\text { errors } \\
1 \%\end{array}$ \\
\hline 2009 & 874961 & 858729 & 1.86 & 865445 & 1.09 & 869664 & 0.61 & 869799 & 0.59 \\
\hline 2010 & 927805 & 910345 & 1.88 & 918350 & 1.02 & 922724 & 0.55 & 921918 & 0.63 \\
\hline 2011 & 970000 & 965058 & 0.51 & 974489 & 0.46 & 978351 & 0.86 & 976693 & 0.69 \\
\hline
\end{tabular}

\subsection{Forecasting Method Comparison for the Total Power of China's Agricultural Machinery}

The fitting mean absolute percentage error is $0.59 \%$ for the nonlinear combined forecast model based on BP neural network, which is lower than the selected exponential model, grey GM $(1,1)$ model and cubic exponential smoothing model of $2.57 \%, 2.66 \%$ and $2.09 \%$. The validation forecast was carried out for the total power of agricultural machinery from 2009 to 2011 using different methods. The results show that the test samples error is $0.64 \%$ for combined forecast model based on BP neural network, which has the best forecasting effect. For nonlinear combined forecast model based on BP neural network has higher fitting precision and higher forecast precision, therefore this model can effectively improve the forecast precision of total power of China's agricultural machinery. The total power of agricultural machinery from 2012 to 2020 in China was forecasted using this combined forecast method, the forecasted results are shown in table 3 . 
Table 3. Forecasted results of total power of China's agricultural machinery from 2012 to 2020

\begin{tabular}{|c|c|c|c|c|c|c|c|c|c|}
\hline years & 2012 & 2013 & 2014 & 2015 & 2016 & 2017 & 2018 & 2019 & 2020 \\
\hline $\begin{array}{l}\text { forecasted } \\
\text { value /MW }\end{array}$ & 03 & 1945 & $13 / 1$ & & 2935 & & 4410 & & 603498 \\
\hline
\end{tabular}

\section{Conclusions}

In purpose of improving forecast accuracy for the total power of China's agricultural machinery, comprehensive utilizing the effective information provided by each single forecast method, and the nonlinear mapping capability of neural network technology, the nonlinear combined forecast model based on BP neural network was put forward, and the combined forecast model for the total power of China's agricultural machinery was established.

The fitting precision and forecast accuracy of different models for the total power of China's agricultural machinery are compared, the results show that nonlinear combined forecast method based on BP neural network has significantly higher forecast precision than any other single forecast model, which effectively improves the forecast accuracy, and provides a new way to forecast the total power of agricultural machinery. The total power of China's agricultural machinery from 2012 - 2020 was forecasted with this model, and the forecasted results show that the total power of China's agricultural machinery will maintain a rapid growth trend, it will be $1223987.1 \mathrm{MW}$ by 2015 and 1603498.2 MW by 2020, which is consistent with the actual development situation of China's agricultural mechanization, and can provide important theory reference for China's agricultural machinery department to make the development planning of agricultural mechanization, publish relevant policies and apply for the financial support.

\section{References}

1. Zhu, R., Wang, F.: Trend Envelope Predict and Analysis of Heilongiiang Province Agriculture Machinery Total Power. Journal of Northeast Agricultural University 38(4), 512-515 (2006)

2. Zhang, H.: Forecasting of Agricultural Mechanical Total Power and Application Comparison of Multi-mathematic Methods. Chinese Agricultural Mechanization (2), 50-52 (2006)

3. Zhu, R., Huang, Y., Yang, X.: Method for Estimating Total Power of Agricultural Machinery Based on Mixed Grey Neural Network. Transactions of the Chinese Society of Agricultural Engineering 22(2), 107-110 (2006)

4. Zhang, S., Zhao, F.: Combinatorial Forecast of Agricultural Machinery Total Power Based on Shapley Value. Transactions of the Chinese Society for Agricultural Machinery 39(5), 60-64 (2008)

5. Ju, J., Wang, J.: Prediction Method for the Operation Level of Agricultural Mechanization in Heilongjiang Province. Transactions of the Chinese Society of Agricultural Engineering 25(5), 83-88 (2009)

6. Ju, J., Wang, J., Wang, J.: Combined Prediction Method of Total Power of Agricultural Machinery Based on BP Neural Network. Transactions of the Chinese Society for Agricultural Machinery 41(6), 87-92 (2010) 
7. Wang, J., Zhao, Y., Ma, L.: Research on Combination Forecasting Method and Application in Electric Power Load Forecasting. Journal of Northeast Agricultural University 39(4), 51-54 (2008)

8. Aminian, F., Dante Suarez, E., Aminian, M., Walz, D.T.: Forecasting Economic Data with Neural Networks. Computational Economics 28(1), 71-88 (2006)

9. Singh, A.K., Panda, S.S., Chakraborty, D., Pal, S.K.: Predicting Drill Wear using an Artificial Neural Network. The International Journal of Advanced Manufacturing Technology 28(5-6), 456-462 (2006) 